\title{
Failure-to-rescue: An evolving quality metric
}

\author{
Benjamin D. Kozower, MD, MPH
}

See related article on pages 1365-73.

Failure-to-rescue from a postoperative event or complication has received significant attention as a quality metric during the past decade. It is now endorsed by the National Quality Forum and the Agency for Healthcare Research and Quality. Failure-to-rescue provides a measure of a health care providers' ability to recognize and respond to adverse events. An early motivation for using this quality metric was the concern that hospitals might underreport complications or adverse events after surgery. If a complication is recorded, however, the response to that complication provides an important indicator of the quality of care that is delivered. In addition, surgical quality measures such as operative mortality have been hampered by their low event rates. The failure-to-rescue measure benefits from a higher event rate by limiting the study population to patients who have a postoperative event and have a higher risk of operative mortality.

In this edition of the Journal of Thoracic and Cardiovascular Surgery, Farjah and colleagues ${ }^{1}$ present their findings related to failure-to-rescue after pulmonary resection. They studied 30,000 patients undergoing lung cancer resection from more than 200 hospitals participating in the Society of Thoracic Surgeons General Thoracic Surgery Database (GTSD). ${ }^{1}$ As Farjah and colleagues ${ }^{1}$ describe, the GTSD provides the largest available clinical database to perform such an analysis. These data have been externally and independently audited with a data accuracy rate of $95 \%$ and no evidence that providers have tried to "game the system" by excluding patients with poor outcomes from their GTSD reports. Farjah and colleagues ${ }^{1}$ report that failure-to-rescue had considerably more variation among providers than did the occurrence of postoperative complications. Furthermore, Farjah and colleagues ${ }^{1}$ conclude that failure to rescue, and not simply the occurrence of a postoperative complication, is the dominant driver of risk-adjusted

From the Department of General Thoracic Surgery, University of Virginia, Charlottesville, Va.

Disclosures: Author has nothing to disclose with regard to commercial support.

Received for publication Feb 2, 2015; accepted for publication Feb 2, 2015; available ahead of print March 6, 2015.

Address for reprints: Benjamin D. Kozower, MD, MPH, University of Virginia, Box 800679, Charlottesville, VA 22908-0679 (E-mail: bdk8g@ virginia.edu).

J Thorac Cardiovasc Surg 2015;149:1247-8 $0022-5223 / \$ 36.00$

Copyright (C) 2015 by The American Association for Thoracic Surgery http://dx.doi.org/10.1016/j.jtcvs.2015.02.008 mortality. These findings are consistent with many other studies on the topic but have the advantage of using robust clinical data from primarily higher volume, academic hospitals participating in the GTSD.

The Society of Thoracic Surgeons (STS) has taken great care to develop and publish their surgical quality composite models in a rigorous and transparent fashion. ${ }^{2}$ The STS uses Bayesian hierarchical models to create 3 categories for hospital performance according to $95 \%$ credible intervals such that a participating hospital is considered an average or expected performer if their performance and credible intervals cross the average performance. A low- or high-performing center would have a score and credible intervals that do not cross the average. Farjah and colleagues ${ }^{1}$ used a different approach by converting operative mortality from a continuous variable into a categorical variable by means of quintiles. They subsequently compared failureto-rescue across the mortality categories and found that death after complication (failure-to-rescue) was more than $400 \%$ higher at the highest mortality (category 5 ) than at the lowest mortality group (category 1). An important concern with this approach is that categorizing continuous data has the effect of magnifying the apparent odds ratios. ${ }^{3}$ Both failure-to-rescue and operative mortality are continuous variables, and it would be very interesting to see the results with these variables analyzed as such. This point is of practical importance because other quality indicators, such as hospital procedure volume after lung cancer resection, have a much smaller or no association with mortality when measured as continuous rather than categorical variables. ${ }^{4}$ It would also be interesting to compare hospital performance according to the failure-to-rescue measure with a composite measure of mortality and major complications currently used by many of the STS quality models. Finally, this work on failure-to-rescue may be even more critical when considering hospital performance after esophagectomy for esophageal cancer, which has much higher complication and mortality figures than does lung cancer resection.

The important take home message from the work of Farjah and colleagues ${ }^{1}$ is that hospital systems need better understanding of and response to complications to reduce mortality and improve the quality of care that is delivered. As Farjah and colleagues ${ }^{1}$ appropriately point out, this will be critical as health care providers prepare for value-based purchasing in a highly complex medical environment. This work provides an excellent review of the rationale and importance of studying the failure-torescue metric and will be of great interest for the readers of the Journal. 


\section{References}

1. Farjah F, Backhus L, Cheng A, Englum B, Kim S, Saha-Chaudhuri P, et al. Failure-to-rescue and pulmonary resection for lung cancer. $J$ Thorac Cardiovasc Surg. 2015;149:1365-73.

2. Shahian DM, O'Brien SM, Filardo G, Ferraris VA, Haan CK, Rich JB, et al; Society of Thoracic Surgeons Quality Measurement Task Force. The Society of
Thoracic Surgeons 2008 cardiac surgery risk models: part 1—coronary artery bypass grafting surgery. Ann Thorac Surg. 2009;88(1 Suppl):S2-22.

3. Royston P, Altman DG, Sauerbrei W. Dichotomizing continuous predictors in multiple regression: a bad idea. Stat Med. 2006;25:127-41.

4. Kozower BD, Stukenborg GJ. The relationship between hospital lung cancer resection volume and patient mortality risk. Ann Surg. 2011;254:1032-7.

Access to The Journal of Thoracic and Cardiovascular Surgery Online is reserved for print subscribers!

Full-text access to The Journal of Thoracic and Cardiovascular Surgery Online is available for all print subscribers. To activate your individual online subscription, please visit The Journal of Thoracic and Cardiovascular Surgery Online, point your browser to http://www.mosby.com/jtcvs, follow the prompts to activate your online access, and follow the instructions. To activate your account, you will need your subscriber account number, which you can find on your mailing label (note: the number of digits in your subscriber account number varies from 6 to 10). See the example below in which the subscriber account number has been circled:

\section{Sample mailing label}

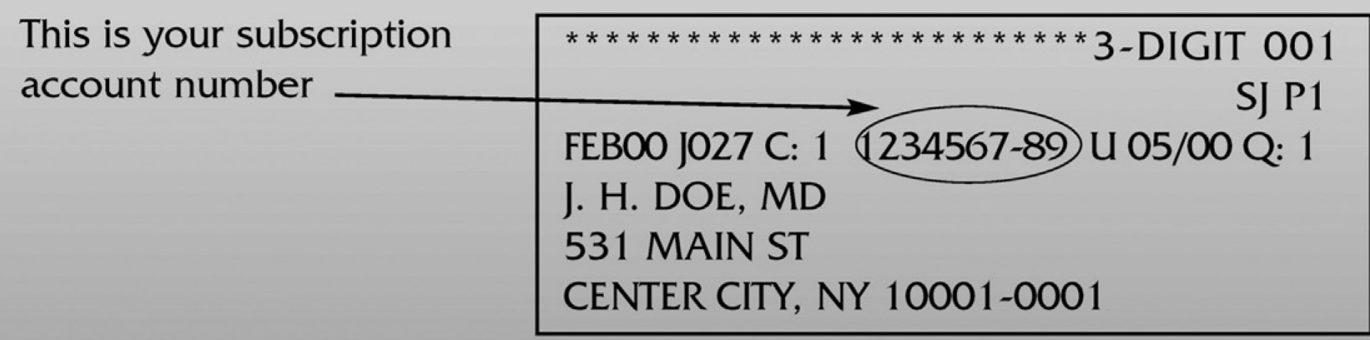

Personal subscriptions to The Journal of Thoracic and Cardiovascular Surgery Online are for individual use only and may not be transferred. Use of The Journal of Thoracic and Cardiovascular Surgery Online is subject to agreement to the terms and conditions as indicated online. 